\title{
Numerical and Experimental Investigation on the Structural Behaviour of a Horizontal Stabilizer under Critical Aerodynamic Loading Conditions
}

\author{
R. Sepe, ${ }^{1}$ R. Citarella, ${ }^{2}$ A. De Luca, ${ }^{3}$ and E. Armentani ${ }^{1}$ \\ ${ }^{1}$ Department of Chemical, Materials and Production Engineering, University of Naples Federico II, P.le V. Tecchio 80, \\ 80125 Naples, Italy \\ ${ }^{2}$ Department of Industrial Engineering, University of Salerno, Via Giovanni Paolo II 132, 84084 Fisciano, Italy \\ ${ }^{3}$ Department of Industrial and Information Engineering, Università della Campania "Luigi Vanvitelli", Via Roma 29, \\ 81031 Aversa, Italy
}

Correspondence should be addressed to R. Sepe; raffsepe@unina.it

Received 4 March 2017; Revised 3 June 2017; Accepted 18 June 2017; Published 27 July 2017

Academic Editor: Paulo M. S. T. De Castro

Copyright (c) 2017 R. Sepe et al. This is an open access article distributed under the Creative Commons Attribution License, which permits unrestricted use, distribution, and reproduction in any medium, provided the original work is properly cited.

\begin{abstract}
The aim of the proposed research activity is to investigate the mechanical behaviour of a part of aerospace horizontal stabilizer, made of composite materials and undergoing static loads. The prototype design and manufacturing phases have been carried out in the framework of this research activity. The structural components of such stabilizer are made of composite sandwich panels (HTA 5131/RTM 6) with honeycomb core (HRH-10-1/8-4.0); the sandwich skins have been made by means of Resin Transfer Moulding (RTM) process. In order to assess the mechanical strength of this stabilizer, experimental tests have been performed. In particular, the most critical inflight recorded aerodynamic load has been experimentally reproduced and applied on the stabilizer. A numerical model, based on the Finite Element Method (FEM) and aimed at reducing the experimental effort, has been preliminarily developed to calibrate amplitude, direction, and distribution of an equivalent and simpler load vector to be used in the experimental test. The FEM analysis, performed by using NASTRAN code, has allowed modelling the skins of the composite sandwich plates by definition of material properties and stack orientation of each lamina, while the honeycomb core has been modelled by using an equivalent orthotropic plate. Numerical and experimental results have been compared and a good agreement has been achieved.
\end{abstract}

\section{Introduction}

In order to improve the performance of transport systems, many companies are spending resources to find a way for achieving structural lightweight and strength. As a result, several studies are made for substituting traditional materials with more efficient ones. So, new structural solutions, based on innovative materials, are often applied in such fields. As a matter of fact, advanced materials, such as composites, represent an efficient solution to these problems. However, their application is affected by critical aspects, due to their sensitivity to notch effect, environmental conditions, damaging under low velocity impacts, and so on. There are many works in literature showing the application and investigation on aerospace structural components entirely made of composite materials. In order to investigate the structural behaviour of aircraft composite components, also several experimental tests can be found in literature. A common approach to investigate and study the phenomena involved during in-service/critical loading conditions is based on the joint usage of both Finite Element Method (FEM) and laboratory experimental tests.

Bossak and Kaczkowski [1] investigated the crashworthiness of a lightweight composite aircraft. A full scale finite element model was provided in such work, in an attempt to investigate the phenomena involving a crash landing event, with a focus on the passenger's safety.

Wittenberg et al. [2] investigated, by FEM modeling and experimental tests, the postbuckling phenomenon, involving 
stiffened shear panels of ultra-high capacity aircraft under compression loading conditions.

Linde et al. [3] investigated different modelling techniques and solution methods for the study of the postbuckling behaviour of stiffened aircraft fuselage panels. The virtual testing proposed in such paper is based on the main goal of reducing experimental test efforts, leveraging on virtual parametric models.

Frulla and Cestino [4] carried out their research activities on the design of an autonomous high altitude long-endurance unmanned air vehicle (HALE-UAV) platform. A scaledprototype was designed in order to perform structural static and dynamic tests and the results were compared with numerical and analytical computations. The main structure was made of CFRP materials.

Romano et al. [5] carried out research activities on the design of a new CFRP aileron, considering as a baseline reference an aluminium aileron installed on the P180 AVANTI aircraft. Composite laminates used for such structure were manufactured by using the Resin Transfer Moulding (RTM) process. An iterative design methodology, developed by using both simplified and detailed design approaches, was used in such study, leading to an optimized aileron concept characterized by a strong reduction of the number of the structural subparts and by a considerable increase of the weight/costs ratio. Finally, the effectiveness of the developed full scale demonstrator was successfully assessed at the ultimate static load, satisfying the same test performed for the certification of the aluminium aileron.

Armentani et al. [6] and Citarella et al. [7, 8] carried out studies on a full scale aeronautic panel made of fibre metal laminate, tested under both static and fatigue biaxial loads, applied by means of an innovative multiaxial fatigue machine. The methodology proposed in these papers aims at providing a general purpose evaluation tool for a better understanding of the fatigue resistance of aeronautic panels, providing a deeper insight into the role of fibre stiffness and of delamination extension on the stress intensity factors of a crack in the middle bay. The fatigue test was simulated in [6] by the Dual Boundary Element Method (DBEM) in a bidimensional approach, whereas in [7] a three-dimensional FEM-BEM coupled approach was introduced to better detail the analysis in the cracked area.

Further studies, performed at coupon level and aimed at the characterization of composite materials under both critical and in-service loading conditions, are provided; for example, Schön et al. [9] dealt with end notch composite specimens under bending loading conditions and provided numerical-experimental outcomes concerning the fracture behaviour under both static and cyclic loads.

Jones and Alesi [10] investigated another critical phenomenon involving composite materials when affected by compressive loading conditions. The authors analysed one of the most critical events which can affect a stiffened composite panel, the separation/debonding of the skin from the stiffeners, as a consequence of excessive "through the thickness" stresses. In particular, this paper shows the results of a series of experimental, analytical, and numerical studies,

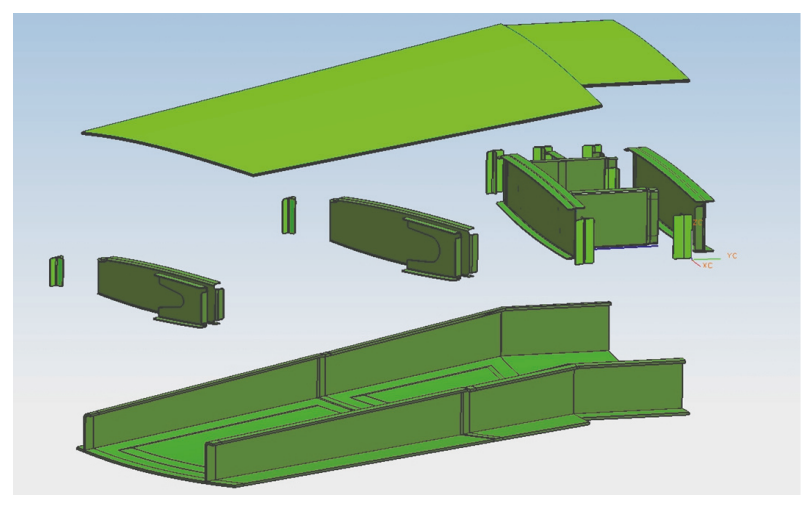

Figure 1: Exploded view of the stabilizer.

aimed at analysing the matrix-dominated failures involving a rib stiffened panel under compression load.

Other authors, such as Caputo et al. [11] and Sepe et al. [12], provided several numerical and experimental investigations on the structural behaviour of aircraft composite components under LVI (low velocity impact) phenomena. The dangerousness of such phenomena is related to the fact that after a LVI a composite panel may return to its original shape without any detectable damage (Barely Visible Impact Damage (BVID)), while it has suffered massive internal damage. The main goal of such research activity consists in the prediction of interlaminar and intralaminar failure mechanisms by means of finite element procedures involving composite components under such loading conditions. According to the numerical-experimental comparison, fibre, matrix, and delamination damage were well predicted by the developed FE model.

The main focus of the work illustrated in this paper is to analyse the mechanical behaviour of a part of aircraft horizontal stabilizer made of composite materials. A prototype of the stabilizer in hand has been designed for such purpose and then manufactured. It was made by composite sandwich panels (HTA 5131/RTM 6) with honeycomb core (HRH-101/8-4.0). The sandwich facing skins were made by means of RTM process $[13,14]$, which is one of the most efficient available technologies for the production of such materials.

Some experimental tests were carried out on the prototype. In particular, the most critical aerodynamic load, recorded during the flights of a small aircraft [15], was experimentally reproduced and applied to the stabilizer.

\section{Materials and Manufacturing of Stabilizer}

An exploded view of the analysed stabilizer is shown in Figure 1. The stabilizer is made out of two skin panels: a lower skin, in which the two main spars (front spar and rear spar) are integrated, and an upper skin. Moreover, there are two ribs between the spars and two root ribs, whose aim is to make the stabilizer end stiffer, providing the needed constraints during the static test. Each rib is bonded by $\mathrm{T}$ clips to the lower skin and to the spars. All parts were manufactured using $51316 \mathrm{~K}$ HexForce G1157 (Hexcel) carbon fibres and LY 5052 (Huntsman) epoxy resin by RTM process. Finally, 
TABLE 1: Staking sequence of each part.

\begin{tabular}{lccc}
\hline Part & Number of plies & Thickness $[\mathrm{mm}]$ & Staking sequence \\
\hline Lower and upper skin & 28 & 7.84 & {$[+45 /-45 / 90 /-45 / 0 / 45 / 90 /-45 / 0 / 45 / 90 /-45 / 45 / 0]_{S}$} \\
Ribs & 9 & 2.52 & {$[+45 / 90 /-45 / 0 / 0 / 0 /-45 / 90 /+45]$} \\
Root ribs & 10 & 2.8 & {$[+45 /-45 / 0 / 90 / 0]_{S}$} \\
T-clips & 10 & 2.8 & {$[+45 /-45 / 0 / 90 / 0]_{S}$} \\
\hline
\end{tabular}

a honeycomb insert core HRH-10-1/8-4.0 (Hexcel) is placed in the central zone, between the lower and upper skin.

In the RTM process the resin is injected into a closed mould filled with dry fibres. Fibre reinforcement is preliminary preformed in order to make its positioning easier in the mould. Such technique allows some benefits, as the possibility of producing net shape and reduced tolerance parts, which provide benefits also during the assembly phase.

The staking sequence of each part is reported in Table 1. All parts were bonded with epoxy bicomponent adhesive HYSOL EA934 N/A (Henkel Aerospace), the weight ratio between mixing resin and hardener being $100: 33$. The grit blasting, using alumina folder strip (220 grit), and the surfaces cleaning and drying (using propanol) were performed to prepare the laminate surfaces for the subsequent bonding. The cure cycle used for the adhesively bonding process was determined based on the associated technical datasheet and the entire process took approximately $108 \mathrm{~h}$ [16].

\section{FE Analyses}

In order to reproduce by experimental tests the critical aerodynamic load condition acting on the stabilizer, FE analyses were performed, by means of NASTRAN code, in order to define an equivalent load system that turns out to be easily reproducible experimentally and, at the same time, allows simulating the structural behaviour of the stabilizer under in-service loads.

3.1. FE Model. All the stabilizer parts were modelled with SHELL elements CQUAD4 (an isoparametric membranebending element with four nodes with six degrees of freedom per node). A global view of the finite element model is shown in Figure 2; it is based on 7783 elements and 7694 nodes. The thickness of each lamina and the fibre orientation were defined using the composite laminates tool. The mechanical properties of the lamina material are reported in Table 2. MSC PATRAN ${ }^{\circledR}$ preprocessor environment was used for modelling the stabilizer and linear static analyses were performed by means of NASTRAN ${ }^{\circledR}$ code.

3.2. Loads and Constraints. A complex loading condition (MB MAX-800xVD-xFL2-2UCU-FUEL: START CRUISE $2544.7 \mathrm{~kg}$ ) [15], corresponding to the most critical aerodynamic loads recorded during the flight (Table 3), will be applied to the stabilizer.

The directions of each load vector are defined in the local system 10 (Figure 3), while the coordinates $X, Y$, and $Z$
TABLE 2: Mechanical material properties of lamina HTA 5131/RTM6.

\begin{tabular}{lc}
\hline Longitudinal Young Modulus, $E_{11}$ & $92.10 \mathrm{GPa}$ \\
Transverse Young Modulus, $E_{22}=E_{33}$ & $7.61 \mathrm{GPa}$ \\
In Plane Shear Modulus, $G_{12}=G_{13}$ & $3.26 \mathrm{GPa}$ \\
In Plane Shear Modulus, $G_{23}$ & $3.26 \mathrm{GPa}$ \\
Poisson ratio, $\nu_{12}=v_{13}$ & 0.36 \\
Poisson ratio, $v_{23}$ & 0.48 \\
Longitudinal tensile strength $X_{t}$ & $1222 \mathrm{MPa}$ \\
Longitudinal compressive strength $X_{c}$ & $654 \mathrm{MPa}$ \\
Transverse tensile strength $Y_{t}=Z_{t}$ & $42.8 \mathrm{MPa}$ \\
Transverse compressive strength $Y_{c}=Z_{c}$ & $104 \mathrm{MPa}$ \\
Shear strength $S_{12}=S_{13}$ & $62.5 \mathrm{MPa}$ \\
Ply thickness & $0.28 \mathrm{~mm}$ \\
\hline
\end{tabular}

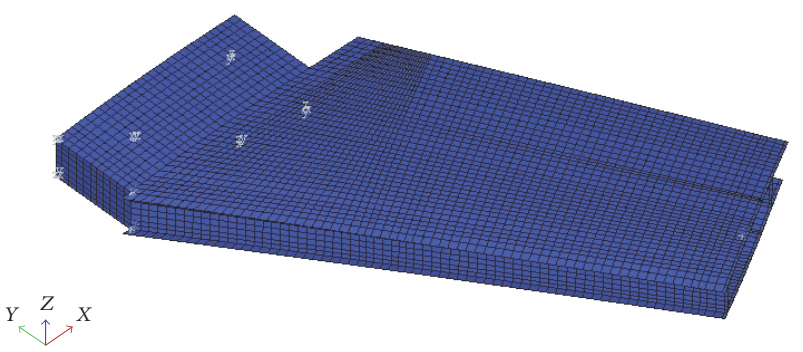

Figure 2: FE model.

reported in Table 3 are referred to the global reference system 0 (Figure 3).

The points of load introduction are put in connection with the stabilizer main structure by means of RBE3 rigid elements, whereas the nodes in the stabilizer rear zone, close to root ribs, are constrained for all six DOFs (Figure 4).

3.3. Equivalent Load System. In order to experimentally reproduce the aforementioned most critical aerodynamic load, FE analyses have been carried out considering different loading conditions. As previously said, the aim of this procedure is to find an equivalent load system, easily reproducible by experimental test but still able to simulate the real structural behaviour of the stabilizer under the true loads.

This equivalent load configuration has been calculated by means of eight linear numerical analyses: each one was performed by applying in turn a unit load on the points shown in Figure 5. Such loads have been applied through the modelled test pads (Figure 5). 
TABLE 3: Load point position and load components.

\begin{tabular}{lccccccccc}
\hline ID position load & $X[\mathrm{~mm}]$ & $Y[\mathrm{~mm}]$ & $Z[\mathrm{~m}]$ & $F_{x}[\mathrm{~N}]$ & $F_{y}[\mathrm{~N}]$ & $F_{z}[\mathrm{~N}]$ & $M_{x}[\mathrm{~N} \cdot \mathrm{m}]$ & $M_{y}[\mathrm{~N} \cdot \mathrm{m}]$ & $M_{z}[\mathrm{~N} \cdot \mathrm{m}]$ \\
\hline$P_{1}$ & 477 & -330 & 0 & -83.2 & 182.2 & -6081.2 & -27 & -30 & -136 \\
$P_{2}$ & 660 & -630 & 0 & -169.6 & 231.3 & -7556.9 & -39 & -272 \\
$P_{3}$ & 992 & -1170 & 0 & -200.2 & 254.5 & -9042.1 & -38 & -167 \\
$P_{4}$ & 1286 & -1650 & 0 & -180.9 & 221.0 & -19659.3 & 47 & -141 \\
\hline
\end{tabular}

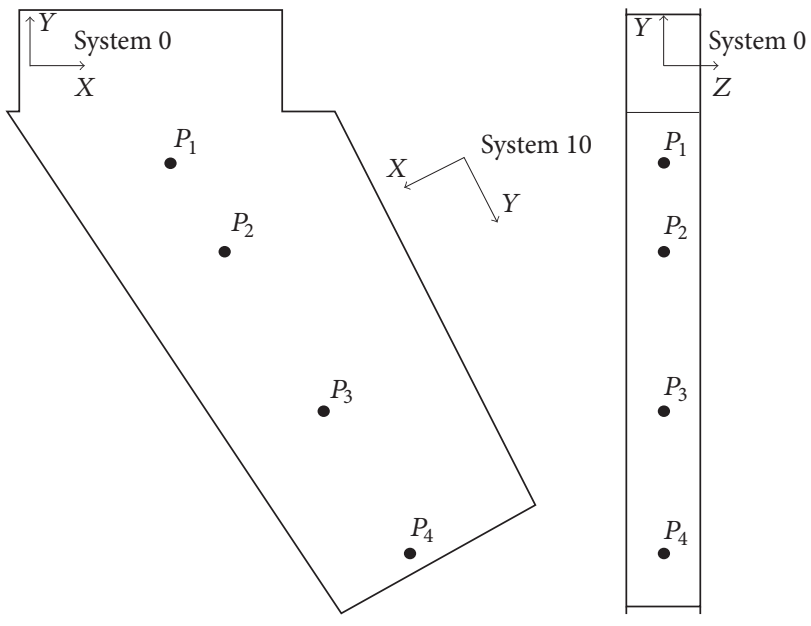

FIGURE 3: Reference system and lading point.

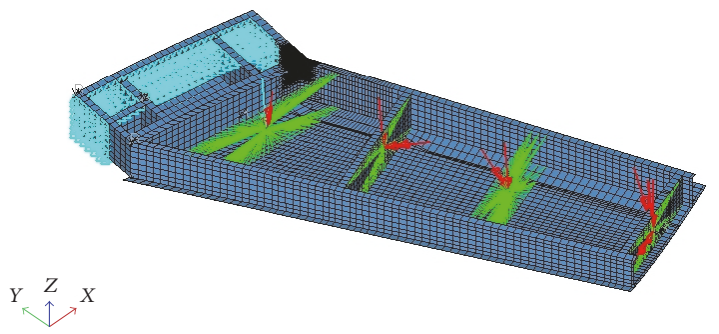

FIGURE 4: Loads and boundary conditions.

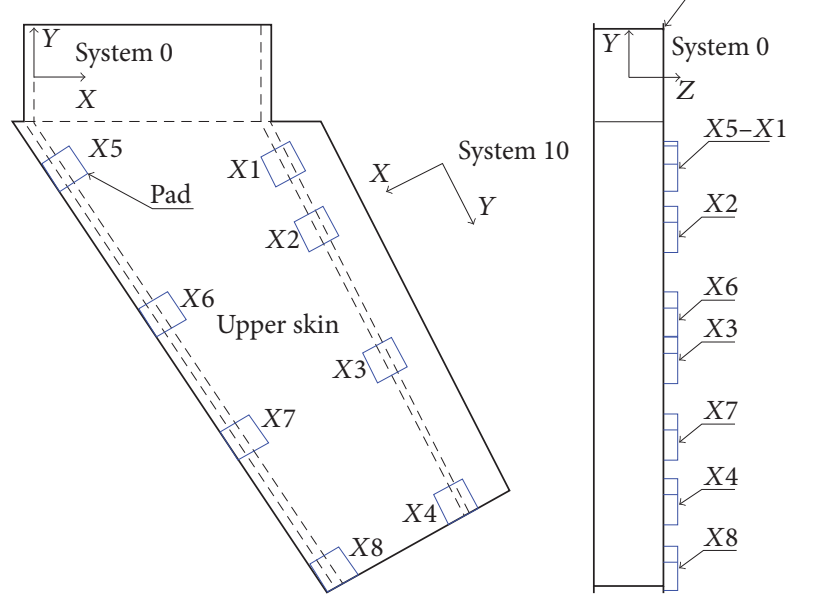

Figure 5: Modelled test pads.
Finding an equivalent loads system means to set up a linear combination of elementary loads able to reproduce the stabilizer deflection recorded in the FE analysis considering the real load system. The new load configuration can be calculated by using

$$
E\left(X_{1}, X_{2}, \ldots, X_{8}\right)=\sum_{h=1}^{N_{\text {dof }}}\left[\sum_{k=1}^{8}\left(u_{h, k} \cdot X_{k}\right)-\bar{u}_{h}\right]^{2},
$$

where

$E\left(X_{1}, X_{2}, \ldots, X_{8}\right)$ is the error function to minimize; $X_{1}, X_{2}, \ldots, X_{8}$ are the weights of such linear combination (they correspond to the load amplitudes of the new equivalent load system);

$u_{h, k}$ is the translational displacement of $h$ th degree of freedom due to the $k$ th unit force;

$\bar{u}_{h}$ is the translational displacement of $h$ th degree of freedom due to the loads shown in Table 3;

$N_{\text {dof }}$ is the number of translational degrees of freedom of the whole model (equal to 23082).

In order to apply only downwards vertical forces, the unknown linear combination coefficients $X_{1}, X_{2}, \ldots, X_{8}$ cannot be negative. So in order to find the minimum of the error function, the following constraints must be added:

$$
\begin{aligned}
& X_{1} \geq 0 \\
& X_{2} \geq 0 \\
& X_{3} \geq 0 \\
& X_{4} \geq 0 \\
& X_{5} \geq 0 \\
& X_{6} \geq 0 \\
& X_{7} \geq 0 \\
& X_{8} \geq 0 .
\end{aligned}
$$

In more detail, the new loads configuration come out from the combination of the 8 coefficients $X_{1}, X_{2}, \ldots, X_{8}$ that minimizes the sum of squared differences between the displacements caused by the new loads system and those caused by the loads system shown in Table 3 . The minimum square differences were calculated by MATLAB ${ }^{\circledR}$ code with lsqnonneg function, which can retrieve the solution by means of the algorithm reported in [17]. Therefore, it is possible 
TABLE 4: Equivalent loads system.

\begin{tabular}{lccccc}
\hline ID position (Figure 5) & Load & $X[\mathrm{~mm}]$ & $Y[\mathrm{~mm}]$ & $Z[\mathrm{~mm}]$ & $F_{z}[\mathrm{~N}]$ \\
\hline$X_{4}$ & $P_{\mathrm{EQ} 1}$ & 1520 & -1515.7 & 63.3 & -16204.4 \\
$X_{8}$ & $P_{\mathrm{EQ} 2}$ & 1069.9 & -1761.6 & 63.3 & -13790.8 \\
\hline
\end{tabular}

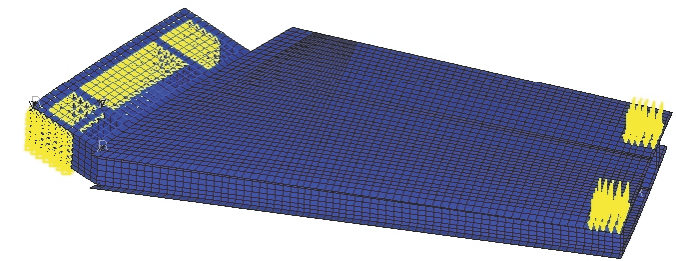

$Y_{\nwarrow \uparrow}^{Z} X$

FIGURE 6: Equivalent load system and boundary conditions.

to simulate experimentally the load condition reported in Table 3 by means of the application of only two forces, as reported in Table 4.

The coordinates $X, Y$, and $Z$ and the load component $F_{z}$ reported in Table 4 are referred to the global reference system 0 (Figure 3 ). The equivalent load system and boundary conditions are reported in Figure 6.

3.4. Results and Discussion. In order to check the accuracy of the new equivalent model, some considerations have been made. The equivalent load system (Table 4) causes a maximum deflection equal to $25.69 \mathrm{~mm}$ (Figure 7), with a difference from the deflection caused by the real load system (Table 3 ) equal to $1.64 \%$.

The respective strain fields contour plots are also consistent: the maximum strains among all the plies, in tension and in compression, along the local $x$ direction, are shown in Figures 8 and 9, respectively. Difference between the maximum strains due to the real load system (Table 3 ) and equivalent load system (Table 4 ) is equal to $-0.000028(1.09 \%)$ while in compression it is equal to $-0.000075(2.64 \%)$.

Likewise, the maximum strain, among all the plies, in tension and in compression, along the local $y$ direction is shown in Figures 10 and 11, respectively. The difference between maximum strains due to the real load system (Table 3) and equivalent load system (Table 4) is equal to $-0.000028(1.09 \%)$ while in compression it is equal to -0.000075 (2.64\%).

The maximum in-plane shear strain among all the plies is shown in Figure 12: the difference between strains due to two different loading conditions is equal to 0.000084 (2.64\%).

Displacements along the spars for the real and equivalent load systems are shown in Figure 13(a). The curves relative to displacements measured, for example, along the paths (red lines) shown in Figure 13(b) are well matching. There is a small difference (lower than 6.3\%) only at the spar ends: this is due to the presence of pads, responsible for an increase of the structure stiffness in the area of load application.
In conclusion, the illustrated results confirm that the load system reported in Table 4 can be considered as equivalent to the real load system reported in Table 3.

\section{Experimental Test}

The equivalent load configuration has been experimentally reproduced in laboratory (Figure 14), applying the load system by means of two pads (in-plane sizes $30 \times 30 \mathrm{~mm} \times$ $\mathrm{mm})$.

Two hydraulic cylinders (Eland HD 20) with load cell of $20 \mathrm{kN}$ have been used to apply the loads. In order to check the stabilizer displacements, 6 transducers (range $0-500 \mathrm{~mm}$ ) have been applied on it. The stabilizer has been constrained by means of two "C" beams joined to the support fixture by means of 10 bolts M16 (Figure 15). Two compliant plates (same curvature of the skin) are bonded to the skin with PLEXUS MA420 adhesive in order to enforce a continuity constraint.

Before starting with the test, the constraints efficiency has been checked by partial application $(40 \%)$ of the equivalent loads. The stabilizer has been instrumented by strain gages, located on the upper and lower skin. Fifteen strain gages, type CEA-13-250UW-350 of MM Vishay, were bonded on the specimen. The strain gages $S_{1}-S_{8}$ (Figure 16(a)) provide the strains on the upper skin, while $S_{9}-S_{15}$ (Figure 16(b)) provide those on the lower skin. All strain gages provide the strains along spanwise direction. The strain gages were bonded by a two-component epoxy adhesive in order to ensure good performance in case of large strains and each strain gage was attached to an acquisition system through a quarter bridge connection. The strain gages position coordinates $(X, Y, Z)$ are reported in Table 5 and are referred to the global reference system 0 (Figure 16).

The values of strain and loads measured during experimental test are reported in Table 6 while the strain versus load $P_{\mathrm{EQ} 1}$ (chosen parameter) is shown in Figure 17.

Numerical strains, provided along the strain gage directions, are compared with the corresponding experimental data in Table 7 in order to validate the overall numericalexperimental procedure. The numerical strains obtained with the equivalent load system (Table 4) may be considered in good agreement with the strain gages outcomes (e.g., lower than $8.5 \%$ relative difference). In fact, the results of strain gages $S_{2}$ and $S_{8}$, which are on the upper skin, are affected by the presence of ribs nearby $S_{2}$ and of a pad nearby $S_{8}$ (load introduction area). Again, the relative difference between numerical and strain gage values on the inferior skin is lower than $8.5 \%$ but for strain gages $S_{12}, S_{13}$, and $S_{15}$. In particular, $S_{12}$ and $S_{13}$ results are affected by secondary bending effects, whereas the $S_{15}$ strain gages are bonded in a low stress zone. 
TABLE 5: Strain gages positions on stabilizer (see reference system in Figure 16).

\begin{tabular}{|c|c|c|c|c|}
\hline Strain gage & $X[\mathrm{~mm}]$ & $Y[\mathrm{~mm}]$ & Skin & Direction \\
\hline$S_{1}$ & 387.9 & -152.9 & Upper & Along spanwise \\
\hline$S_{2}$ & 893.5 & -591.2 & Upper & Along spanwise \\
\hline$S_{3}$ & 1265.9 & -1023.5 & Upper & Along spanwise \\
\hline$S_{4}$ & 1459.8 & -1567.6 & Upper & Along spanwise \\
\hline$S_{5}$ & 205.5 & -493.9 & Upper & Along spanwise \\
\hline$S_{6}$ & 522.1 & -799.7 & Upper & Along spanwise \\
\hline$S_{7}$ & 766.4 & -1328.0 & Upper & Along spanwise \\
\hline$S_{8}$ & 1144.2 & -1743.1 & Upper & Along spanwise \\
\hline$S_{9}$ & 393.5 & -151.1 & Lower & Along spanwise \\
\hline$S_{10}$ & 878.6 & -363.8 & Lower & Along spanwise \\
\hline$S_{11}$ & 1238.4 & -1048.0 & Lower & Along spanwise \\
\hline$S_{12}$ & 218.0 & -486.5 & Lower & Along spanwise \\
\hline$S_{13}$ & 792.5 & -1392.3 & Lower & Along spanwise \\
\hline$S_{14}$ & 692.7 & -700.5 & Lower & Along spanwise \\
\hline$S_{15}$ & 1295.1 & -1647.5 & Lower & Along spanwise \\
\hline
\end{tabular}

Contour plot

Displacement $(Z)$

Analysis system

$\begin{array}{ll} & 2.059 E-03 \\ - & -2.900 E+00\end{array}$

$-5.802 E+00$

$-8.704 E+00$

$-1.161 E+01$

$-1.451 E+01$

$-1.741 E+01$

$-2.031 E+01$

$-2.321 E+01$

$-2.612 E+01$

No result

$\operatorname{Max}=2.059 E-03$

Node 4599

Min $=-2.612 E+01$

Node 1153
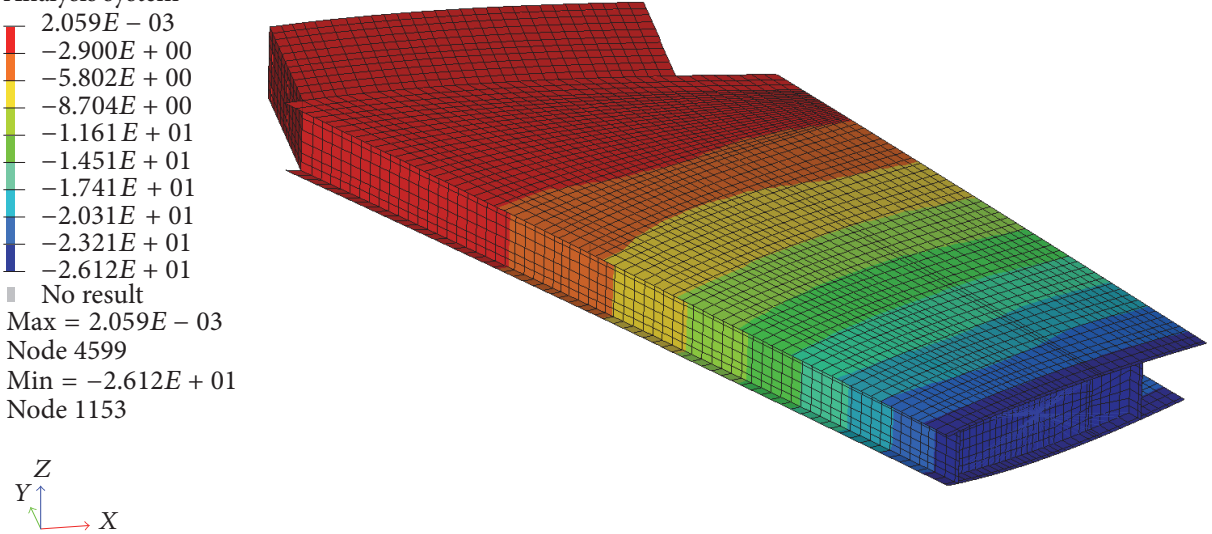

(a)

Contour plot

Displacement $(Z)$

Analysis system

T 2.014E-03

$-2.853 E+00$

$-5.707 E+00$

$-8.562 E+00$

$-1.142 E+01$

$-1.427 E+01$

$-1.713 E+01$

$-1.998 E+01$

$-2.283 E+01$

$-2.569 E+$
No result

$\operatorname{Max}=2.014 E-03$

Node 4599

Min $=-2.569 E+01$

Node 1836
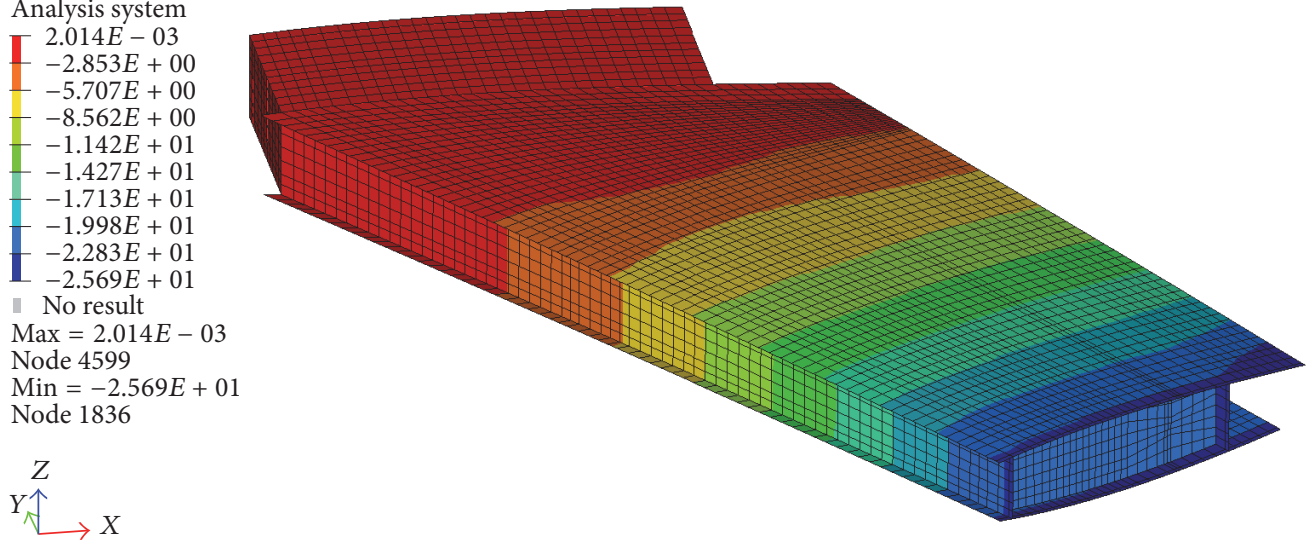

(b)

FIGURE 7: Deflection [mm] along $z$-direction due to real system load (a) and equivalent system load (b). 


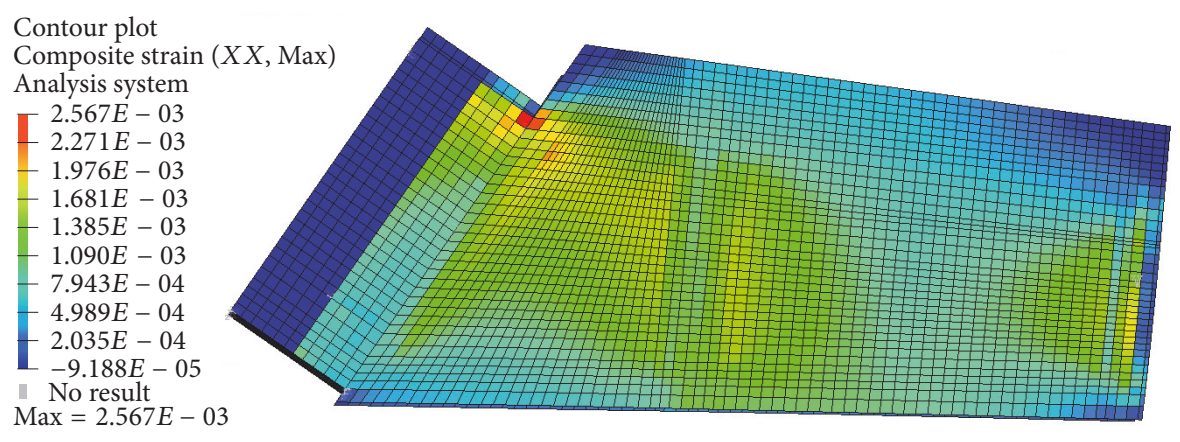

(a)
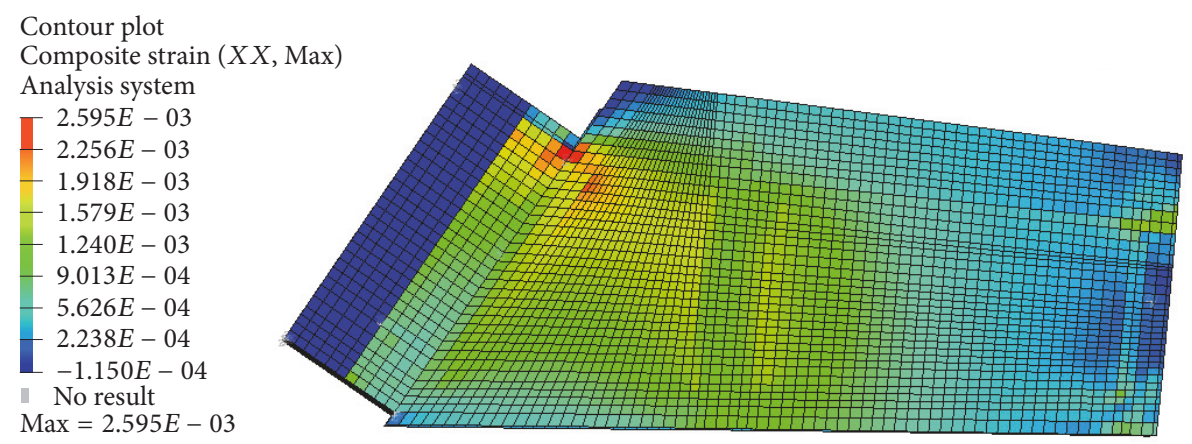

(b)

FIGURE 8: Maximum strain, among all the plies, in tension along the local $x$-axes, due to real load system (a) and equivalent load system (b).

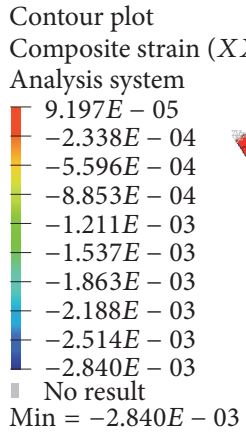

Composite strain $(X X, \mathrm{Min})$

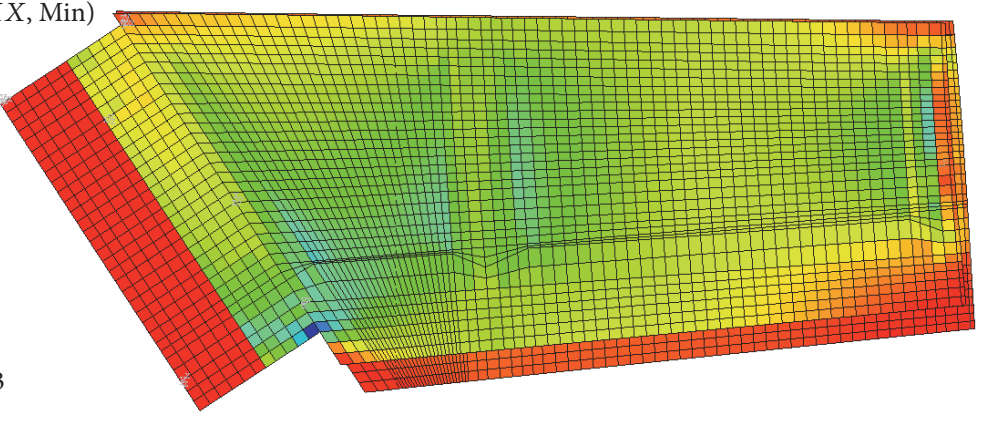

(a)
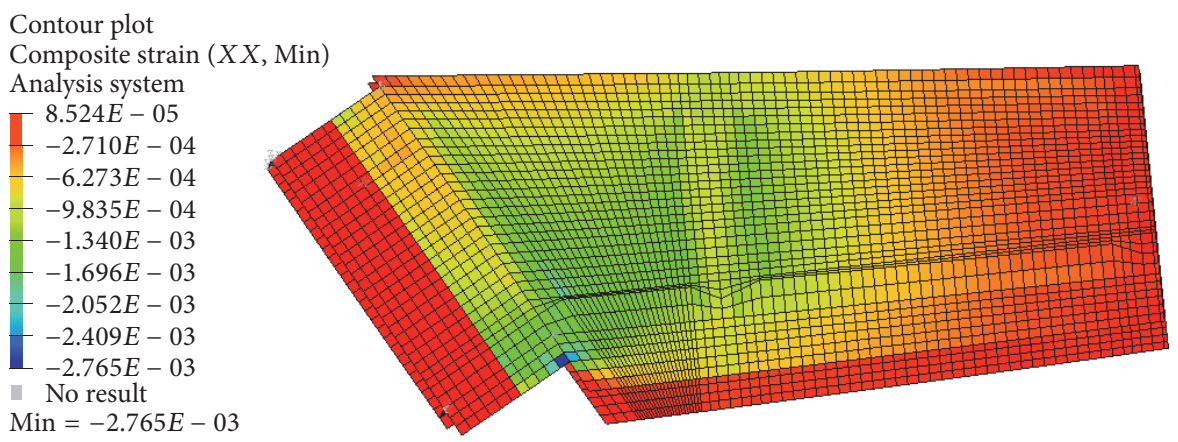

(b)

FIGURE 9: Maximum strain, among all the plies, in compression along the local $x$-axes, due to real load system (a) and equivalent load system (b). 


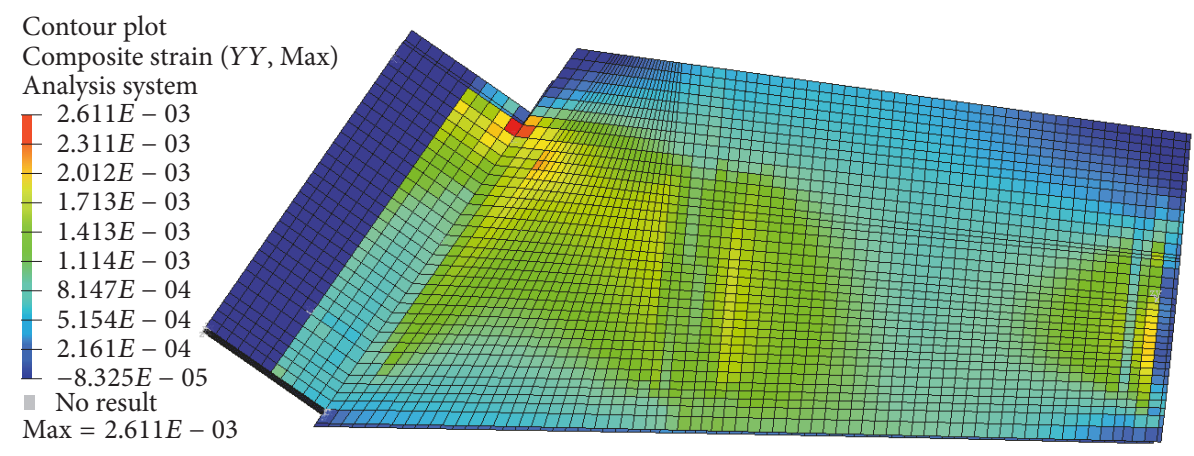

(a)
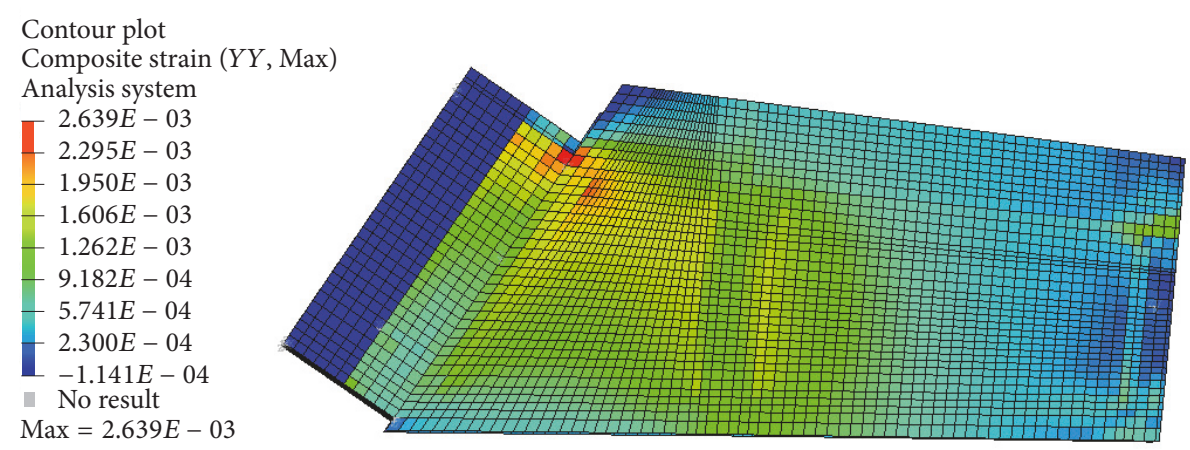

(b)

FIGURE 10: Maximum strain, among all the plies, in tension along the local $y$-axes, due to real system load (a) and equivalent system load (b).

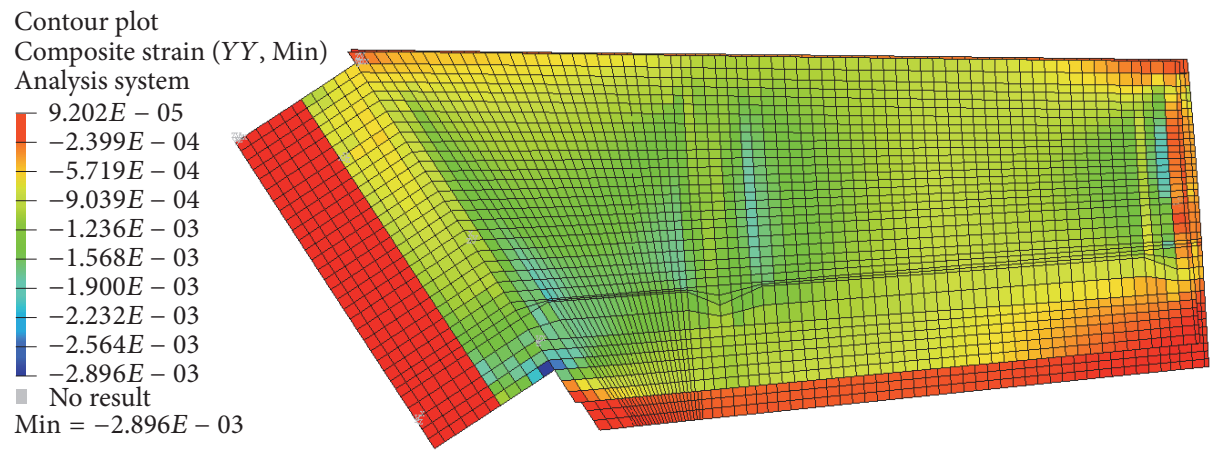

(a)

Contour plot

Composite strain $(Y Y$, Min $)$

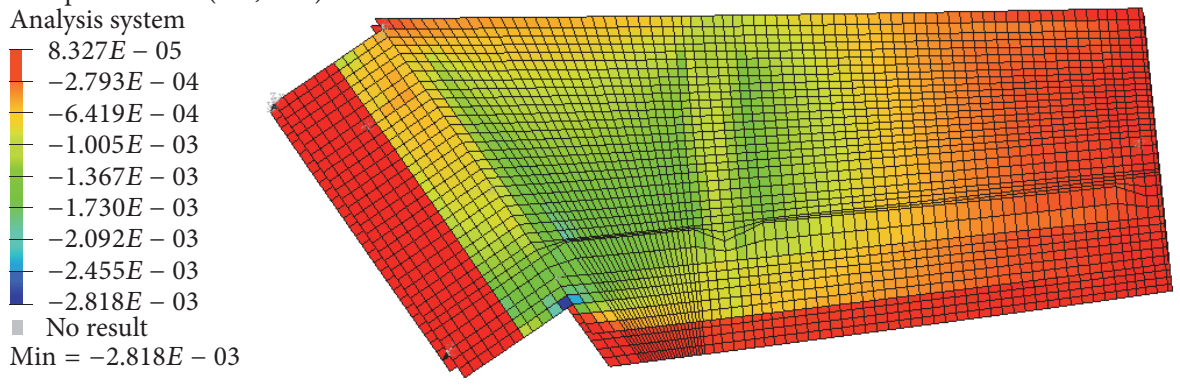

(b)

FIGURE 11: Maximum strain, among all the plies, in compression along the local $y$-axes, due to real system load (a) and equivalent load system (b). 


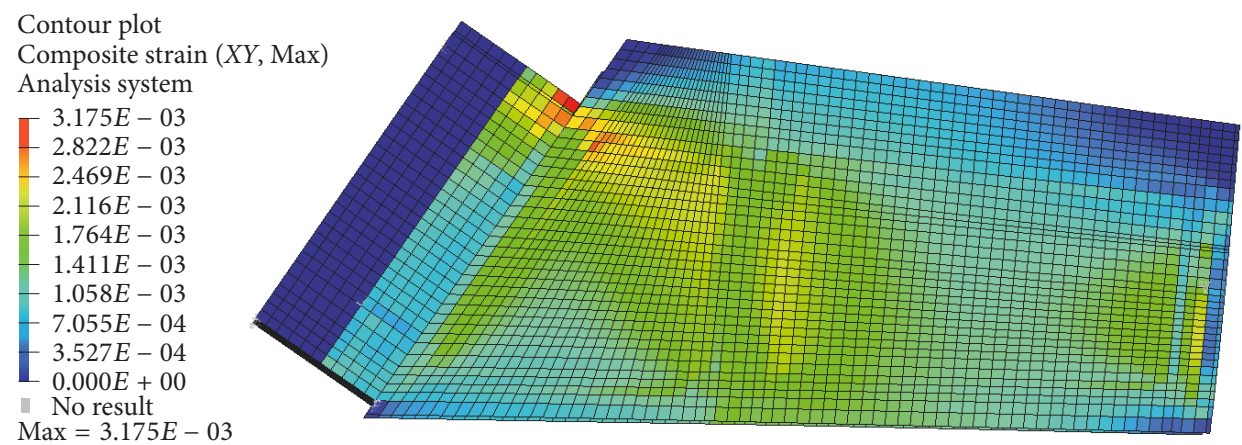

(a)
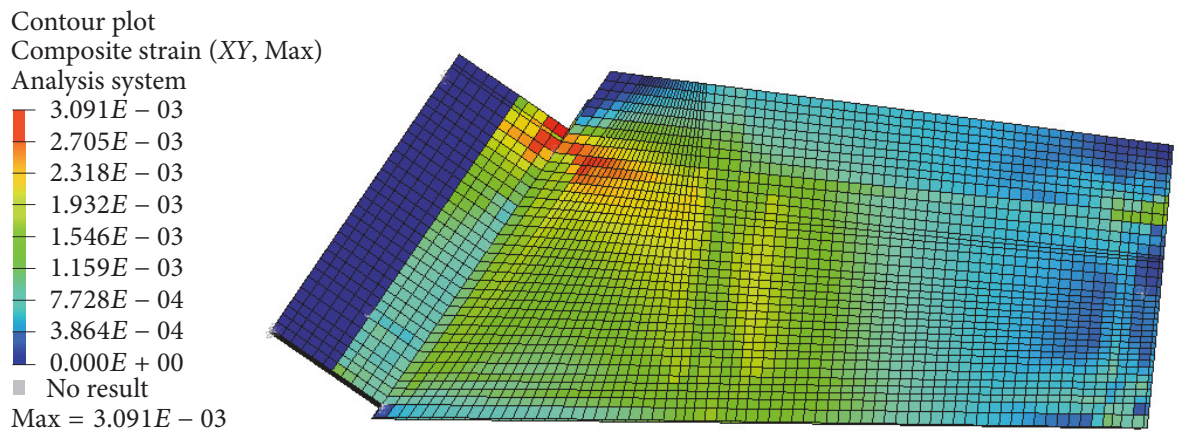

(b)

FIGURE 12: Maximum in-plane shear strain, among all the plies, along local $x$ - and $y$-axis, due to real system load (a) and equivalent load system (b).

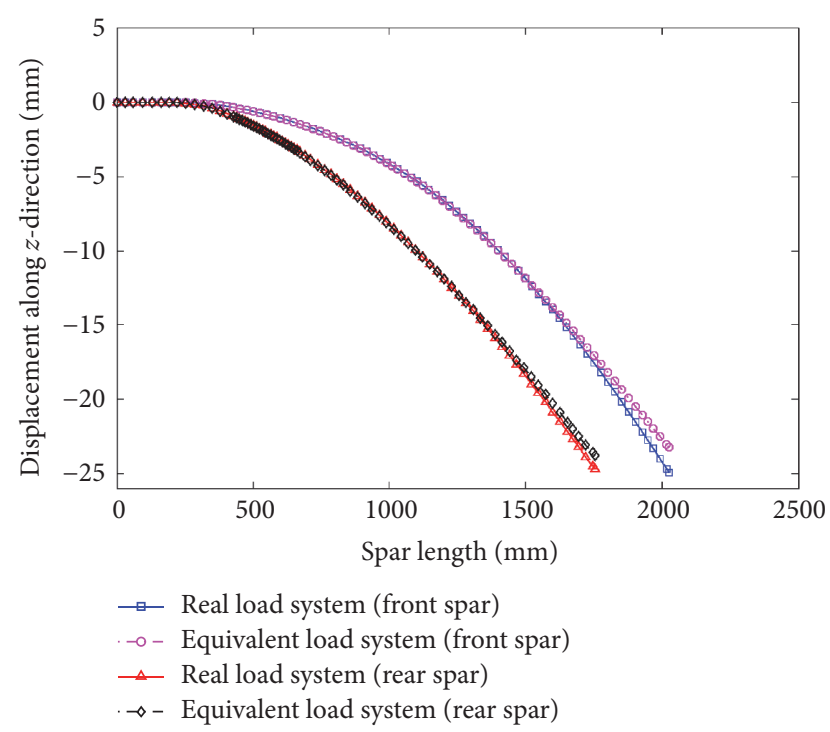

(a)

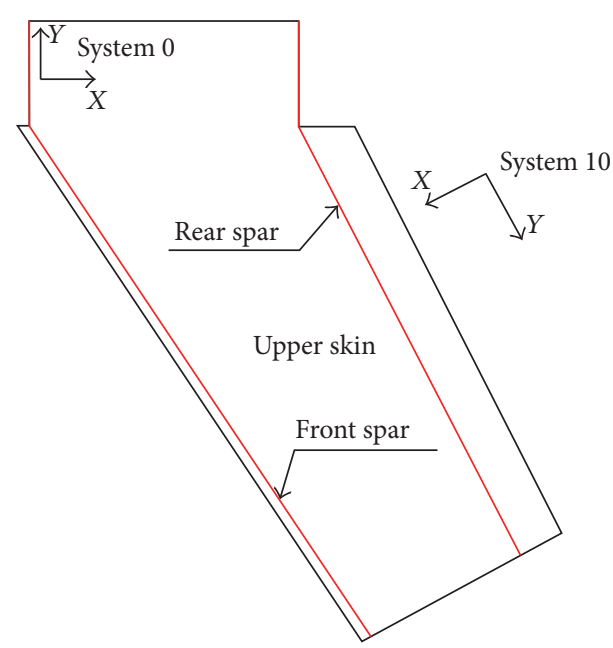

(b)

FIGURE 13: Displacement variation along the spars (a); paths along which the displacements are measured (b).

\section{Conclusions}

A FE numerical model has been developed for studying the best way to experimentally simulate an aerodynamic load in terms of amplitude, direction, and distribution of equivalent forces. Related experimental tests have been illustrated, with a good agreement achieved between numerical and experimental results. 
TABLE 6: Values of strain and loads measured during experimental tests.

\begin{tabular}{lccccccccccccccccc}
\hline \multicolumn{2}{c}{ Load $[\mathrm{N}]$} & \multicolumn{10}{c}{ Strain $[\mu \mathrm{m} / \mathrm{m}]$} \\
$P_{\mathrm{EQ} 1}$ & $P_{\mathrm{EQ} 2}$ & $S_{1}$ & $S_{2}$ & $S_{3}$ & $S_{4}$ & $S_{5}$ & $S_{6}$ & $S_{7}$ & $S_{8}$ & $S_{9}$ & $S_{10}$ & $S_{11}$ & $S_{12}$ & $S_{13}$ & $S_{14}$ & $S_{15}$ \\
\hline 5 & 3 & 0 & -1 & 0 & 1 & 0 & 1 & 0 & 0 & -1 & 0 & 1 & 0 & 1 & -1 & -1 \\
-3114 & -2769 & 208 & 290 & 174 & 46 & 149 & 231 & 105 & 8 & -126 & -182 & -87 & -96 & -63 & -122 & -5 \\
-6329 & -5518 & 416 & 567 & 340 & 87 & 295 & 451 & 205 & 14 & -252 & -373 & -176 & -197 & -136 & -250 & -14 \\
-9522 & -8284 & 617 & 848 & 513 & 136 & 441 & 677 & 309 & 23 & -372 & -554 & -261 & -290 & -197 & -368 & -18 \\
-12761 & -11027 & 816 & 1126 & 683 & 182 & 582 & 897 & 413 & 32 & -493 & -744 & -349 & -386 & -266 & -491 & -24 \\
-16200 & -13786 & 1006 & 1398 & 850 & 229 & 723 & 1110 & 517 & 43 & -607 & -929 & -435 & -478 & -333 & -609 & -29 \\
\hline
\end{tabular}

TABLE 7: Numerical and experimental correlation for equivalent loading condition.

\begin{tabular}{lccc}
\hline Strain gage & $\begin{array}{c}\text { FEM strain }(a) \\
{[\mu \mathrm{m} / \mathrm{m}]}\end{array}$ & $\begin{array}{c}\text { Experimental strain }(b) \\
{[\mu \mathrm{m} / \mathrm{m}]}\end{array}$ & $\begin{array}{c}\text { Deviation }=(a-b) * 100 / b \\
{[\%]}\end{array}$ \\
\hline$S_{1}$ & 920.78 & 1006 & -8.5 \\
$S_{2}$ & 1126.63 & 1398 & -19.4 \\
$S_{3}$ & 783.19 & 850 & -7.88 \\
$S_{4}$ & 242.10 & 229 & 5.67 \\
$S_{5}$ & 664.13 & 723 & -8.14 \\
$S_{6}$ & 1157.87 & 1110 & 4.31 \\
$S_{7}$ & 558.58 & 517 & 8.04 \\
$S_{8}$ & 23.52 & 43 & -45.3 \\
$S_{9}$ & -654.01 & -607 & 7.74 \\
$S_{10}$ & -1005.10 & -929 & 8.19 \\
$S_{11}$ & -460.56 & -435 & 5.87 \\
$S_{12}$ & -650.11 & -478 & 36.00 \\
$S_{13}$ & -389.21 & -333 & 16.81 \\
$S_{14}$ & -585.83 & -609 & -3.80 \\
$S_{15}$ & -24.23 & -29 & -16.43 \\
\hline
\end{tabular}

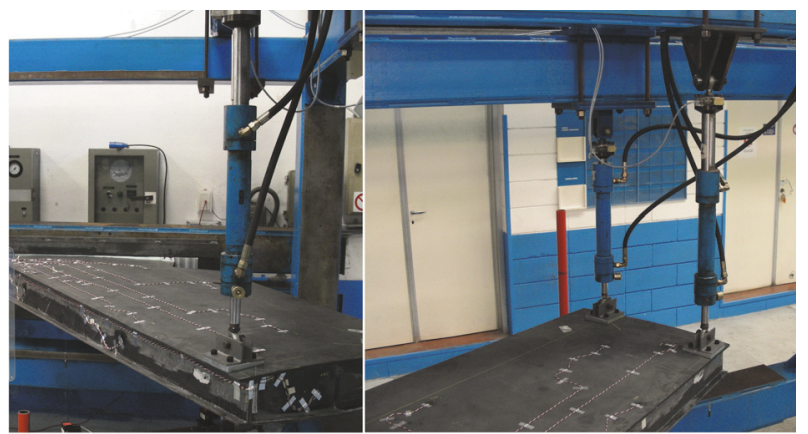

FIGURE 14: Experimental testing setup.

According to the performed static test, in fact, the experimental-numerical differences in most cases are comparable to the intrinsic error level inherent in the strain gage usage.

Hence the proposed numerical model appears to be an efficient method to design quasi-static experimental tests for the investigation of the mechanical behaviour of an aerospace horizontal stabilizer made of composite materials and undergoing aerodynamic loading conditions.

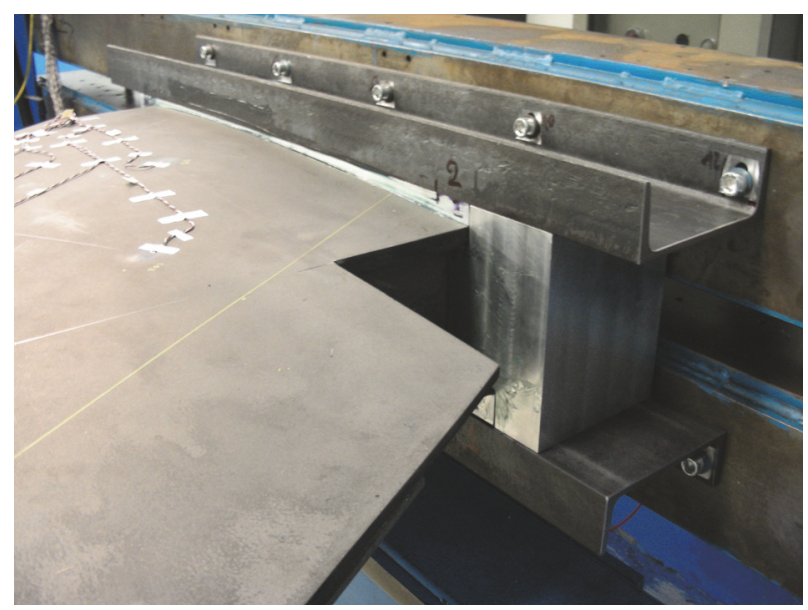

FIGURE 15: Support fixture.

\section{Conflicts of Interest}

The authors declare that there are no conflicts of interest regarding the publication of this paper. 


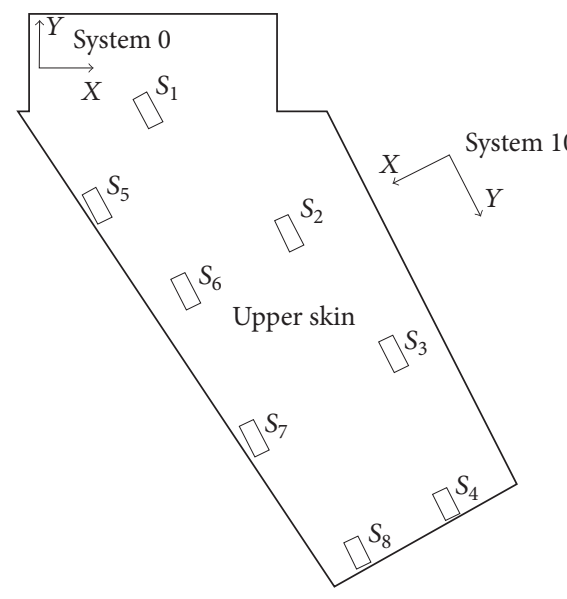

(a)

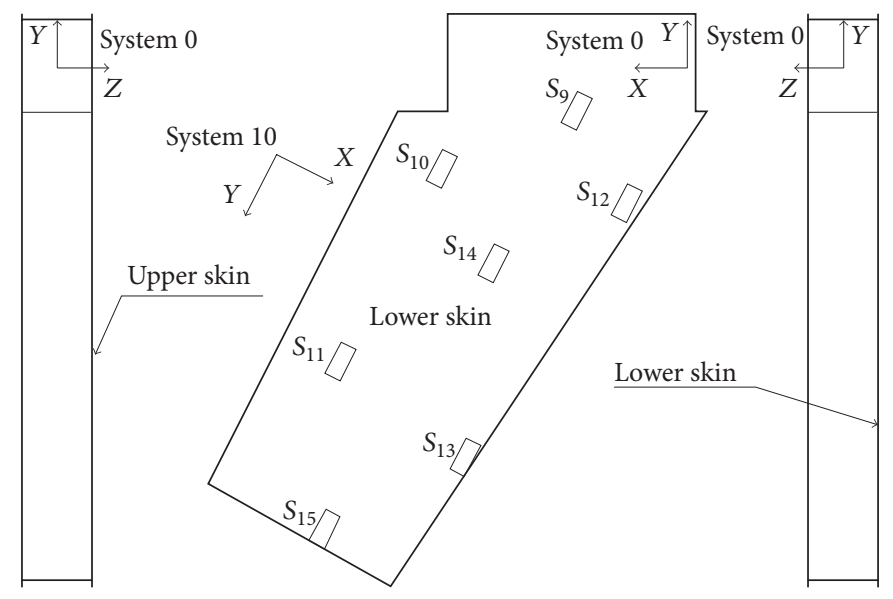

(b)

FIGURE 16: Strain gages' layout.

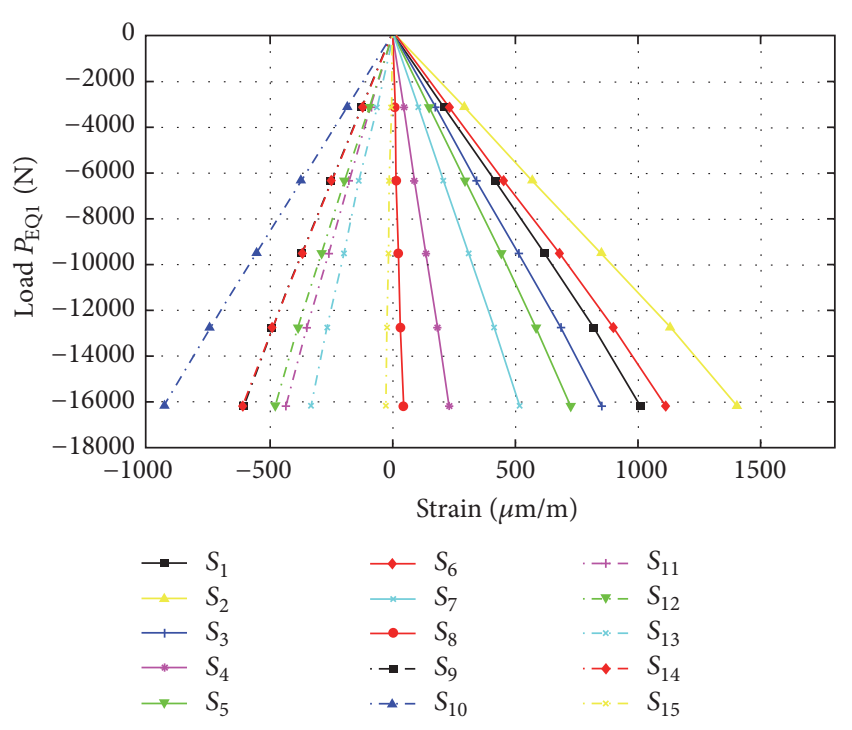

FIGURE 17: Load versus strain curve of experimental data.

\section{Acknowledgments}

The authors would like to thank Piaggio Aerospace S.p.A. for its support and contribution to experimental tests.

\section{References}

[1] M. Bossak and J. Kaczkowski, "Global/local analysis of composite light aircraft crash landing," Computers and Structures, vol. 81, no. 8-11, pp. 503-514, 2003.

[2] T. C. Wittenberg, T. J. Van Baten, and A. De Boer, "Design of fiber metal laminate shear panels for ultra-high capacity aircraft," Aircraft Design, vol. 4, no. 2-3, pp. 99-113, 2001.

[3] P. Linde, A. Schulz, and W. Rust, "Influence of modelling and solution methods on the FE-simulation of the post-buckling behaviour of stiffened aircraft fuselage panels," Composite Structures, vol. 73, no. 2, pp. 229-236, 2006.
[4] G. Frulla and E. Cestino, "Design, manufacturing and testing of a HALE-UAV structural demonstrator," Composite Structures, vol. 83, no. 2, pp. 143-153, 2008.

[5] F. Romano, J. Fiori, and U. Mercurio, "Structural design and test capability of a CFRP aileron," Composite Structures, vol. 88, no. 3, pp. 333-341, 2009.

[6] E. Armentani, R. Citarella, and R. Sepe, "FML full scale aeronautic panel under multiaxial fatigue: experimental test and DBEM Simulation," Engineering Fracture Mechanics, vol. 78, no. 8, pp. 1717-1728, 2011.

[7] R. Citarella and G. Cricrì, "Three-dimensional BEM and FEM submodelling in a cracked FML full scale aeronautic panel," Applied Composite Materials, vol. 21, no. 3, pp. 557-577, 2014.

[8] R. Citarella, V. Ascione, M. Lepore, and C. Calì, "Fatigue crack propagation using the dual boundary element method in a fiber metal laminates aeronautic full scale panel," in Proceedings of the 7th International Conference on Engineering Computational Technology, Valencia, Spain, September 2010.

[9] J. Schön, T. Nyman, A. Blom, and H. Ansell, "Numerical and experimental investigation of a composite ENF-specimen," Engineering Fracture Mechanics, vol. 65, no. 4, pp. 405-433, 2000.

[10] R. Jones and H. Alesi, "On the analysis of composite structures with material and geometric non-linearities," Composite Structures, vol. 50, no. 4, pp. 417-431, 2000.

[11] F. Caputo, A. De Luca, and R. Sepe, "Numerical study of the structural behaviour of impacted composite laminates subjected to compression load," Composites Part B: Engineering, vol. 79, pp. 456-465, 2015.

[12] R. Sepe, A. De Luca, G. Lamanna, and F. Caputo, "Numerical and experimental investigation of residual strength of a LVI damaged CFRP omega stiffened panel with a cut-out," Composites Part B: Engineering, vol. 102, pp. 38-56, 2016.

[13] B. R. Gebart, "Permeability of unidirectional reinforcements for RTM," Journal of Composite Materials, vol. 26, no. 8, pp. 11001133, 1992.

[14] R. S. Hansen, "RTM Processing and Applications," EM 90-214, SME Technical Paper, 1990.

[15] Piaggio Aero Industries S.p.A., P1XX Program-Empennage FE Analysis, Centro di ricerca e sviluppo Piaggio Aero Industries S.p.A., Pozzuoli (NA), 2010. 
[16] G. Lamanna, R. Sepe, and A. Pozzi, "Tensile testing of hybrid composite joints," in Proceedings of the 3rd International Conference on Materials Engineering and Automatic Control (ICMEAC '14), vol. 575 of Applied Mechanics and Materials, pp. 97-100, Tianjin, China, May 2014.

[17] C. L. Lawson and R. J. Hanson, Solving Least Squares Problems, Prentice-Hall, Englewood Cliffs, NJ, USA, 1974. 

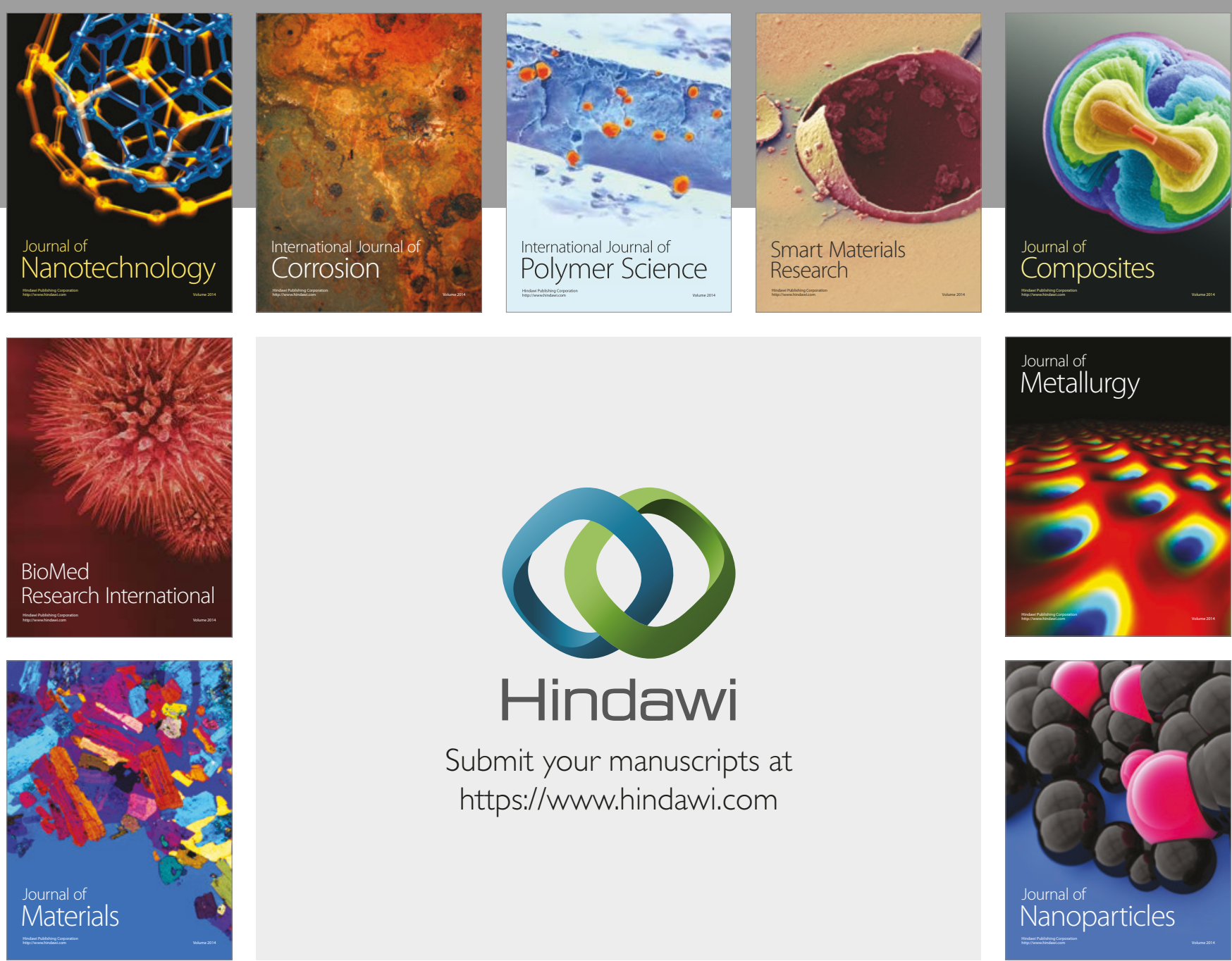

\section{Hindawi}

Submit your manuscripts at

https://www.hindawi.com
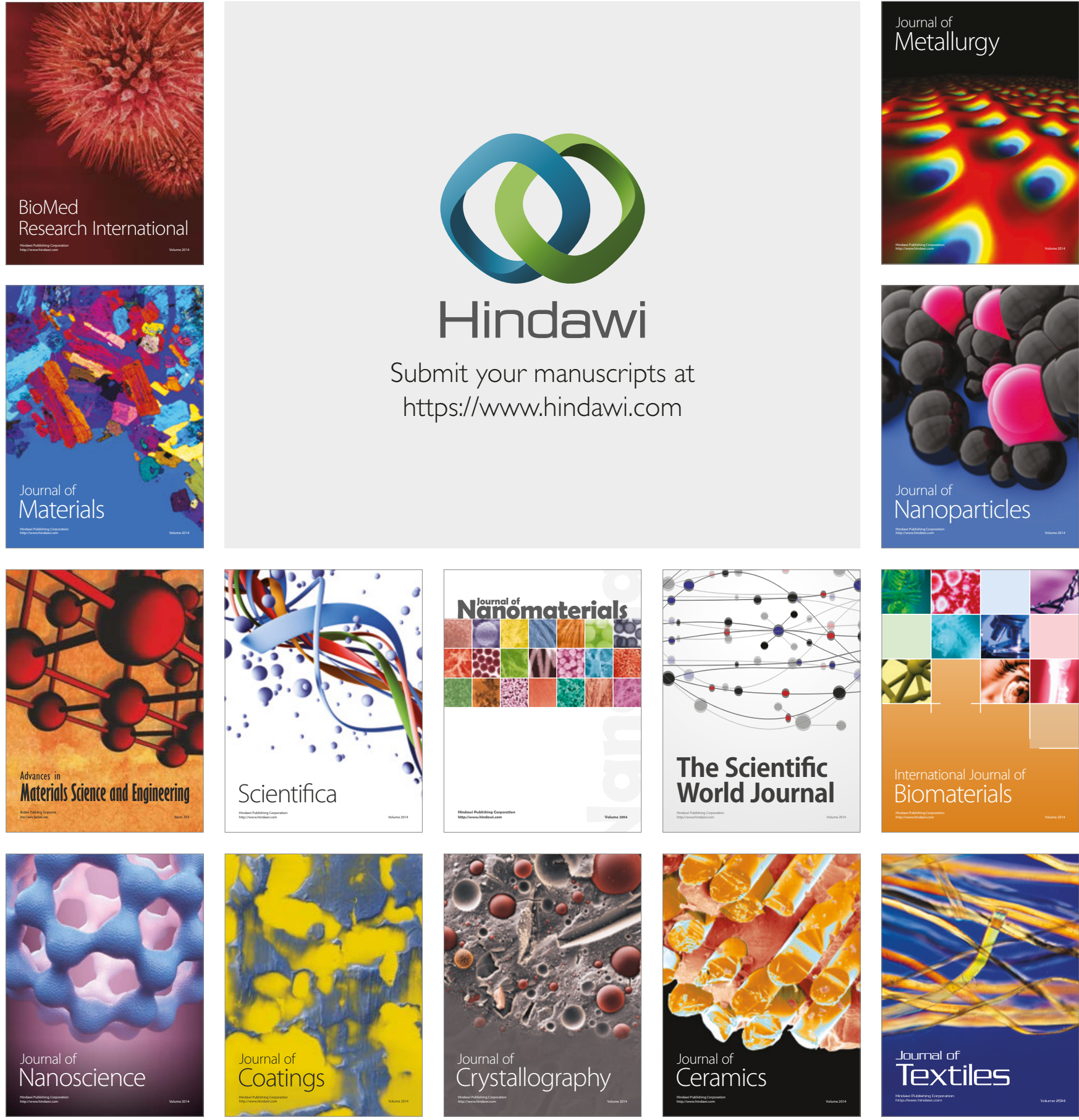

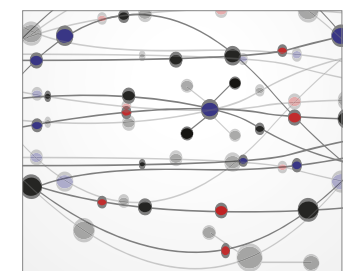

The Scientific World Journal
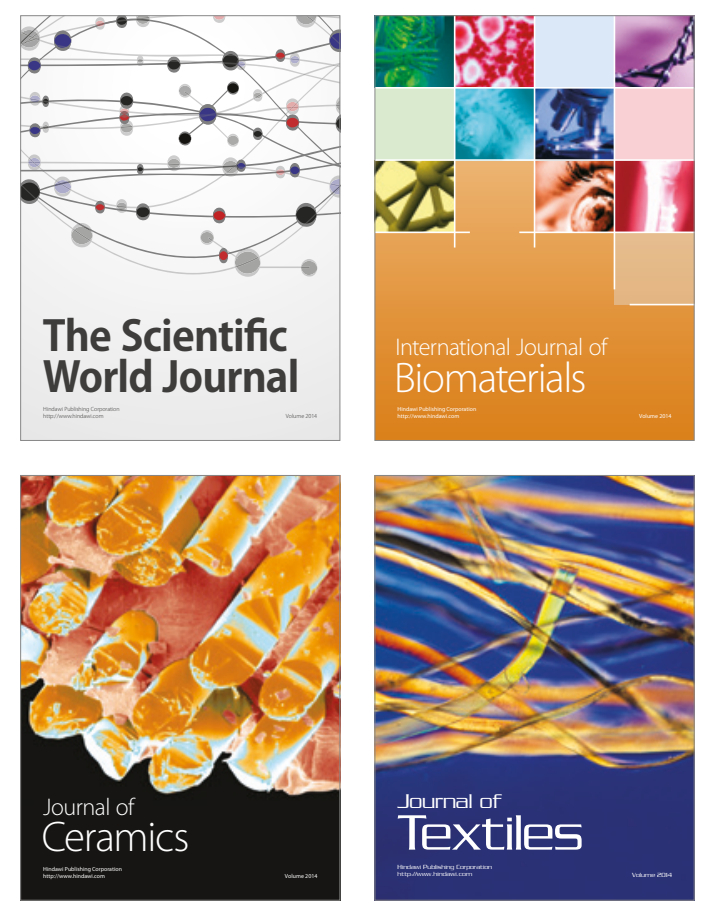